\title{
Repeated recall of pictures, words, and riddles: Increasing subjective organization is not sufficient for producing hypermnesia
}

\author{
DAVID G. PAYNE and MICHAEL J. WENGER \\ State University of New York, Binghamton, New York
}

\begin{abstract}
Davis and Dominowski (1986) presented subjects with riddles to solve followed by five recall tests with no intervening study opportunities. They found increasing net recall levels across tests (i.e., hypermnesia), as well as an increase in the degree of organization in recall. In the present experiment, subjects were presented with riddles, pictures, or words. A significant hypermnesic effect was obtained with the riddles and pictures, but not with the words. There were significant and equivalent increases in subjective organization across tests for all three conditions, indicating that an increase in subjective organization across tests is not sufficient to produce hypermnesia. Finally, there were systematic changes in the rate of recalling items across tests, and these may be related to hypermnesia.
\end{abstract}

Hypermnesia refers to an increase in the number of items recalled across either repeated tests or an increasing retention interval. Both encoding and retrieval factors play critical roles in the phenomenon, with an example of the importance of encoding factors being the observation that pictures typically produce a larger hypermnesic effect than do words (Payne, 1986).

The importance of retrieval factors is documented by several facts. First, hypermnesia is typically obtained only when subjects are allowed to attempt to retrieve target items during the retention interval, either as a result of repeated testing (e.g., Roediger \& Payne, 1982) or via covert retrieval during the retention interval (e.g., Shapiro \& Erdelyi, 1974). Second, hypermnesia is easily obtained with free recall tests under conditions that do not produce a hypermnesic effect in recognition (e.g., Payne \& Roediger, 1987). Third, at least for verbal materials, hypermnesia is almost never obtained with very brief recall tests, but it is frequently obtained with longer ones (Payne, 1987).

These and other findings indicate that hypermnesia is a result of the effortful retrieval processes that subjects engage in during the repeated tests and that an adequate theoretical explanation of the phenomenon must take retrieval factors into account. One explanation for hypermnesia that may be able to deal with the effect of retrieval factors is the cumulative recall level hypothesis (Roediger, Payne, Gillespie, \& Lean, 1982), which holds that hypermnesia is related directly to the difference between asymptotic cumulative recall and the number of items recalled on Test 1 . According to this view, the condition that produces the highest level of cumulative recall should be furthest from asymptote at the end of Test 1 , allowing the most room for improvement across subsequent tests.

Correspondence should be addressed to D. G. Payne, Department of Psychology, SUNY-Binghamton, Binghamton, NY 13902-6000.
Erdelyi, Buschke, and Finkelstein (1977) reported data that are problematic for the cumulative recall level hypothesis. Erdelyi et al. presented subjects with pictures, words, or a series of riddles to solve (e.g., "This longish wooden object is used to hit a baseball. What is it?") followed by five recall tests. The picture and riddle conditions showed a hypermnesic effect but the word condition did not. In addition, the riddle group had the lowest recall level on Test 1 and showed the largest hypermnesic effect.

Erdelyi et al.'s (1977) findings are potentially important because they appear to show a case in which, across tests, both the lowest recall (Test 1 net recall) and highest recall (Test 5 net recall and total cumulative recall) were obtained in the same condition. However, this simple experiment has not been replicated, and hence the reliability of some of these findings can be questioned (see Roediger, 1982). For example, although Erdelyi et al. found no advantage of the riddle condition over the word condition on Test 1 , there are numerous demonstrations of recall advantages for generated items over read items, (e.g., Slamecka \& Graf, 1978).

The present experiment provides a replication of Erdelyi et al.'s (1977) study and also addresses a retrieval process issue raised by Davis and Dominowski (1986). Davis and Dominowski employed a riddle encoding condition similar to Erdelyi et al.'s and obtained a significant hypermnesic effect. More importantly, they also found an increase in two measures of subjective organization across the recall tests. Davis and Dominowski's findings suggest that organizational processes operating at the time of testing may affect hypermnesia. Their study does not, however, address the issue of whether increases in subjective organization are either necessary or sufficient for producing hypermnesia.

There were four goals for the present work. First, we wanted to assess the relation between changes in net recall and subjective organization across tests. Second, we 
sought to attempt to replicate the net recall results reported by Erdelyi et al. (1977). Third, we sought to examine the reliability of a generation effect in recall with riddles. Finally, we wanted to examine changes in the rates of item recovery across tests, because these rates have been implicated as important factors affecting hypermnesia (cf. Payne, Hembrooke, \& Anastasi, in press).

\section{METHOD}

\section{Subjects and Design}

Eighty State University of New York at Binghamton undergraduates participated in the study, 20 in a pilot study and 60 in the main experiment. The main experiment had a $3 \times 5$ mixed factorial design, with item type (words, pictures, riddles) manipulated between subjects $(n=20)$ and test (1-5) manipulated within subjects.

\section{Materials}

To ensure that subjects would be able to solve the riddles and produce the desired target items, we first conducted a pilot study in which subjects were given $\mathbf{4 8}$ riddles to solve. The $\mathbf{4 0}$ items that elicited the desired response from all subjects were used as target items in the main experiment.

Subjects in the riddle condition of the main experiment were presented with the riddles selected in the pilot study, the solutions to which were the target items. The subjects in the word and picture conditions were presented with either the names of the target items typed in uppercase letters or line drawings of the target items, taken from Snodgrass and Vanderwart (1980). All stimuli were prepared as slides.

\section{Procedure}

The subjects were tested in groups of 12 or fewer. The subjects in the riddle condition were told that they would see a series of riddles and that their task was to solve each riddle. These subjects were told that their memory for the solutions would be tested after the list had been presented. The subjects in the word and picture conditions were told that they would be presented with a series of slides, each containing one word or picture, and that they would receive a test for their memory of these items. Subjects were not informed of either the type or the number of tests that would be given.

Target items were presented at an 8-sec rate. After the target items were presented, the subjects were given instructions for the first recall test. The subjects were told that the test would be $6 \mathrm{~min}$ long and that they were to try to recall as many items as possible. They were also told that by the end of the test they were to have filled in all 40 lines on their recall sheet, guessing if necessary. They were informed that at the end of each minute of the test they would be asked to draw a line beneath the last item that they had written on their test sheets. At the end of Test 1 (and only Test 1), the subjects who had not written down $\mathbf{4 0}$ items were given an additional minute in which to complete the test. Those who did not write down $\mathbf{4 0}$ items for each subsequent test were dropped from the experiment and replaced with new subjects. (Only 3\% of all subjects tested failed to meet this criterion for inclusion.)

At the end of Test 1 , the subjects were instructed to turn to the next page in their test booklets and were told to try to recall all 40 target items a second time. They were encouraged to use the entire test period to try to recall items and to try to recall more target items on this test than they had on the previous test. The instructions and procedures for Tests 3-5 were identical to those for Test 2 , with the exception that on Test 5 the subjects were told that this would be the last test.

\section{RESULTS AND DISCUSSION}

To examine the relation between hypermnesia and subjective organization, we need to look at changes in subjective organization and net recall levels under conditions in which hypermnesia is or is not obtained. The present experiment provides these needed comparisons, for there were two cases in which hypermnesia was obtained (pictures and riddles) and one in which it was not (words; the hypermnesic effects are discussed in detail below).

Subjective organization across successive tests was assessed using bidirectional pair frequency (Sternberg \& Tulving, 1977), that is, the number of item pairs that are recalled in adjacent serial positions across two successive tests. As Figure 1 indicates, there were large differences in the overall levels of subjective organization for the three item types $\left[F(2,57)=6.70, M S_{\mathrm{e}}=43.95\right]$. (Unless otherwise noted, all effects referred to as significant have an alpha level of .05). Furthermore, organized recall increased across tests in each condition $[F(3,171)=8.96$, $\left.M S_{\mathrm{e}}=3.01\right]$. The magnitude of the increase in subjective organization across test pairs was approximately equal for the three item types (interaction $F<1.0$ ). Simple effects tests revealed a significant main effect of test pairs for each of the item types.

The fact that all three conditions showed significant improvements in subjective organization across test pairs indicates that subjects actively organize the recalled to-beremembered items. However, the fact that this increase occurs and is of the same magnitude when hypermnesia both is and is not obtained (i.e., pictures and riddles vs. words) indicates that an increase in organized recall is not sufficient to produce hypermnesia. Furthermore, the finding that the picture condition produced the highest levels of organized recall but that the riddle condition yielded the largest overall hypermnesic effect (see below for details) casts further doubt on the notion that increases in subjective organization are critical in producing hypermnesia.

The net recall levels on each test for the three item type conditions are presented in Figure 2. The net recall levels differed for the three item types, with pictures producing the highest recall levels, followed by riddles and words $\left[F(2,57)=6.70, M S_{\mathrm{e}}=115.33\right]$. The three conditions also varied in their patterns of change in net recall levels across tests. Both the riddle and the picture conditions produced a sizable hypermnesic effect, whereas the word condition did not. These conclusions are supported by the finding of a main effect of test $\left[F(4,228)=16.30, M S_{\mathrm{e}}=\right.$

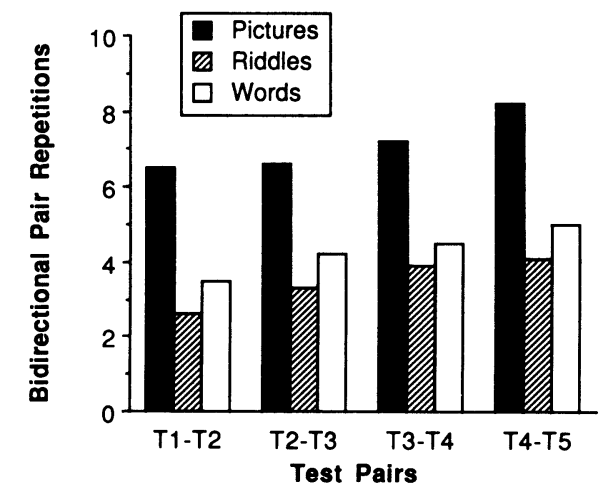

Figure 1. Mean pair frequency for the three item type conditions. 


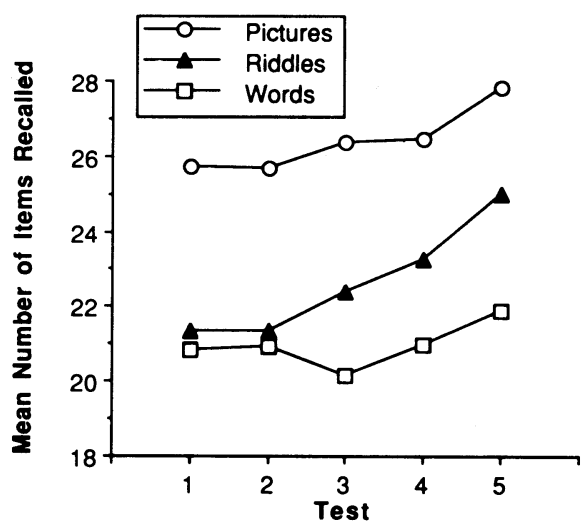

Figure 2. Net recall levels on the five tests for the three item type conditions.

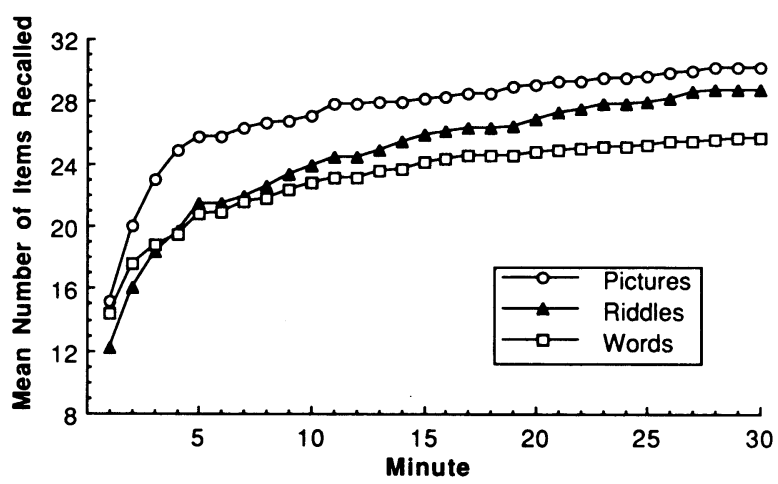

Figure 3. Mean cumulative recall levels across the $30 \mathrm{~min}$ of testing for the three item type conditions.

3.33], and a significant item type $\times$ test interaction $\left[F(8,228)=2.29, M S_{\mathrm{e}}=3.30\right]$. One-way ANOVAs conducted for each item type condition revealed significant hypermnesic effects for the picture $[F(4,76)=5.50$, $\left.M S_{\mathrm{e}}=2.74\right]$ and riddle $\left[F(4,76)=15.43, M S_{\mathrm{e}}=3.02\right]$ conditions, but not for the word condition $[F(4,76)=$ $\left.1.84, M S_{\mathrm{e}}=4.22, p>.13\right]$.

Recall that Erdelyi et al. (1977) reported no significant differences in recall levels between the riddle and word conditions on Test 1 . We replicated this lack of a difference between riddles and words $[t(38)=0.41]$. This result may be due to the fact that in both the Erdelyi et al. and the present experiment, words were presented as single items, whereas the riddle items were presented as sentences. It is possible that subjects in the riddle condition were retrieving the sentence frame and resolving the riddle, a process that should be slower than retrieving single words.

Cumulative recall levels across the test period were computed by giving subjects credit for recalling an item the first time they recovered that item and disregarding any subsequent occurrences of the item on later tests (see Figure 3). There are several important points to note with regard to these data. First, there was a significant differ- ence in the total number of items recovered across conditions $\left[F(2,57)=5.97, M S_{e}=17.77\right]$. Post hoc analyses revealed that the number of items recovered in the word condition was significantly lower than that for either the picture or the riddle condition, but that the latter two conditions did not differ from one another. Second, replicating Erdelyi et al. (1977), the riddle condition produced recall levels similar to that for the word condition during the early portion of the testing period but produced item recovery rates equivalent to that for the picture condition by the end of the testing period.

The cumulative recall data were analyzed with a $3 \times 5$ (item type $\times$ test) mixed-factor ANOVA using the cumulative recall levels at the end of each test as the dependent variable. There were significant main effects of both item type $\left[F(2,57)=5.54, M S_{\mathrm{e}}=91.36\right]$ and test $\left[F(4,228)=186.34, M S_{\mathrm{e}}=1.52\right]$. The item type $\times$ test interaction was also significant $\left[F(8,228)=5.86, M S_{\mathrm{e}}=\right.$ 1.52 ], suggesting that subjects in the riddle condition recovered items more rapidly than did subjects in the picture or word conditions. This conclusion is supported by the results of a $2 \times 5$ (item type: words vs. pictures $\times$ test) mixed-factor ANOVA that showed no item type $\times$ test interaction $(F<1.0)$.

According to the cumulative recall level hypothesis, hypermnesia is determined by the difference between recall levels on Test 1 and the asymptotic cumulative recall level. In the present experiment, the mean differences between Test 1 recall and total cumulative recall (i.e., Minute 30 - Minute 6) were 4.75, 4.80, and 7.35 items for the word, picture, and riddle conditions, respectively. If hypermnesia were determined completely by this difference in recall levels, we would expect that riddles should produce the largest hypermnesic effect and that the hypermnesic effects for the word and riddle conditions should be approximately equal. Although the results for the riddle condition are in line with these predictions, the results obtained with the picture and word conditions are not: of these two conditions, the word condition did not produce a significant hypermnesic effect. As in previous studies, this picture-word difference is attributable to differences in the rate of intertest forgetting obtained with these items.

Table 1 presents the intertest forgetting and item recovery rates for the three item type conditions. These data were analyzed with a 2 (component of recall: intertest forgetting vs. item recovery) $\times 3$ (item type: picture, word,

Table 1

Mean Intertest Forgetting and Item Recovery Between Successive Tests for the Three Item Type Conditions

\begin{tabular}{lllllll}
\hline \multirow{2}{*}{$\begin{array}{c}\text { Item } \\
\text { Type }\end{array}$} & \multirow{2}{*}{$\begin{array}{c}\text { Component } \\
\text { of Recall }\end{array}$} & \multicolumn{5}{c}{ Test Pair } \\
\cline { 3 - 6 } Words & Intertest forgetting & 2.20 & 2.3 & $3-4$ & $4-5$ & $M$ \\
& Intertest recovery & 2.25 & 2.20 & 1.75 & 1.55 & 2.11 \\
Pictures & Intertest forgetting & 2.20 & 1.55 & 1.80 & 1.15 & 1.68 \\
& Intertest recovery & 2.15 & 2.25 & 1.90 & 2.50 & 2.20 \\
Riddles & Intertest forgetting & 3.05 & 2.40 & 2.05 & 1.85 & 2.33 \\
& Intertest recovery & 3.20 & 3.45 & 2.90 & 3.50 & 3.26 \\
\hline
\end{tabular}




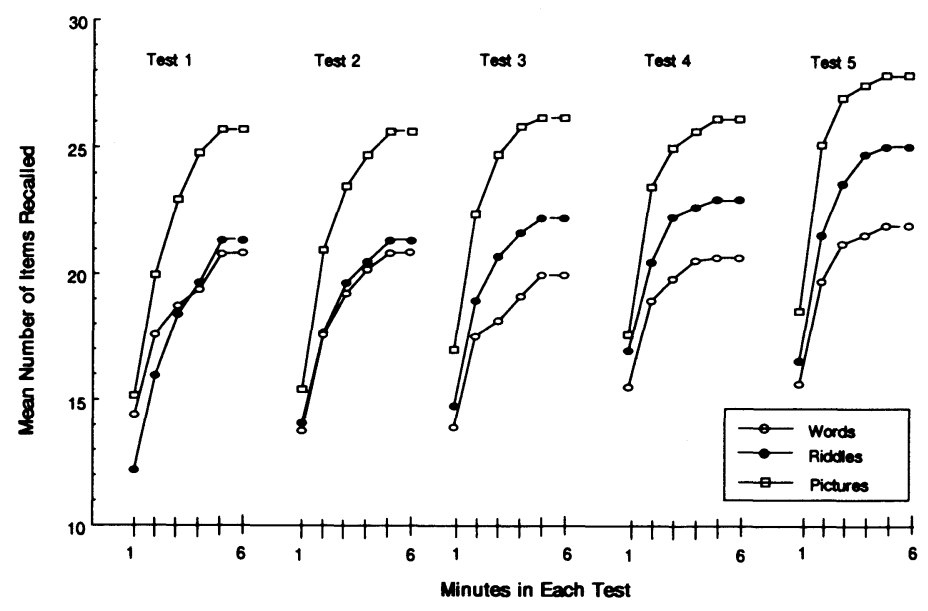

Figure 4. Mean cumulative recall levels within each test for each of the three item type conditions.

riddle) $\times 4$ (test pairs: $1-2,2-3,3-4,4-5)$ mixed-factor ANOVA. The three item types differed in terms of the overall rates of item fluctuation, with pictures producing the lowest rate, followed by words and then riddles $\left[F(2,57)=4.4, M S_{\mathrm{e}}=7.01\right]$. The item recovery rate exceeded the intertest forgetting rate $[F(1,57)=36.84$, $M S_{\mathrm{e}}=1.00$ ], although the difference between these two measures varied significantly as a function of the item type $\left[F(2,57)=4.75, M S_{\mathrm{e}}=1.00\right]$. Replicating previous studies (e.g., Roediger \& Payne, 1982), the item recovery rate was fairly stable across test pairs, whereas the interest forgetting rate showed a consistent decline across tests $\left[F(3,171)=3.16, M S_{\mathrm{e}}=2.96\right]$.

Finally we examined the rate at which items were recalled within each of the tests (see Figure 4). These data indicated that the rate of item recovery increases across tests in each of the three conditions. This is consistent with the retrieval dynamics approach proposed by Payne et al. (in press). Another important point to note is that subjects in the riddle condition had the slowest rate of item recovery during the initial portion of Test 1 but across tests showed a consistent increase in item recovery rate.

In summary, four conclusions follow from the data. First, changes in subjective organization (as measured by bidirectional pair frequency), while revealing something of the dynamics involved as a result of repeated recall attempts, do not predict hypermnesia. Second, the net and cumulative recall results originally reported by Erdelyi et al. (1977) are robust. Third, the item recovery data demonstrate that (1) increases are obtainable with all three stimulus materials, and (2) although item recovery is initially slow with riddles, this may be due simply to the demand on subjects to consider both the riddle as context and the solution as target when recovering items. Fourth, there is clear evidence that recalling items results in an increase in the rate of item recovery for many types of encoding conditions but that different materials are likely to show differential rates of item loss and intertest forgetting. These four conclusions point both to the impor- tance of considering retrieval factors in hypermnesia and to the possible complexity of retrieval factors in producing increased recall.

\section{REFERENCES}

Davis, S. C., \& Dominowski, R. L. (1986). Hypermnesia and the organization of recall. Bulletin of the Psychonomic Society, 24, 31-34.

ERdelyi, M., BuschKe, H., \& Finkelstein, S. (1977). Hypermnesia for Socratic stimuli: The growth of recall for an internally generated memory list abstracted from a series of riddles. Memory \& Cognition, 5, 283-286.

PAYNe, D. G. (1986). Hypermnesia for pictures and words: Testing the recall level hypothesis. Journal of Experimental Psychology: Learning, Memory, \& Cognition, 12, 16-29.

PAYNE, D. G. (1987). Hypermnesia and reminiscence in recall: A historical and empirical review. Psychological Bulletin, 101, 5-27.

Payne, D. G., Hembrooke, H. A., \& Anastasi, J. S. (in press). Hypermnesia in free and cued recall. Memory \& Cognition.

PAyne, D. G., \& Roediger, H. L., III (1987). Hypermnesia occurs in recall but not in recognition. American Journal of Psychology, 100, 145-165.

RoEdiger, H. L., III (1982). Hypermnesia: The importance of recall time and asymptotic level of recall. Journal of Verbal Learning \& Verbal Behavior, 21, 662-665.

Roediger, H. L., III, \& PAYNe, D. G. (1982). Hypermnesia: The role of repeated testing. Journal of Experimental Psychology: Learning, Memory \& Cognition, 8, 66-72.

Roediger, H. L., III, PAyne, D. G., Gillespie, G. L., \& Lean, D. S. (1982). Hypermnesia as determined by level of recall. Journal of Verbal Learning \& Verbal Behavior, 21, 635-655.

Shapiro, S. R., \& ERDELYI, M. H. (1974). Hypermnesia for pictures but not for words. Journal of Experimental Psychology, 103, 1218-1219.

Slamecka, N. J., \& Graf, P. (1978). The generation effect: Delineation of a phenomenon. Journal of Experimental Psychology: Human Learning \& Memory, 4, 592-604.

SNOdGRASS, J. G., \& VANDERWART, M. (1980). A standardized set of 260 pictures: Norms for name agreement, image agreement, familiarity, and visual complexity. Journal of Experimental Psychology: Human Learning \& Memory, 6, 174-215.

SternberG, R. J., \& TUlving, E. (1977). The measurement of subjective organization. Psychological Bulletin, 84, 539-556.

(Manuscript received May 13, 1992.) 